\title{
A novel device for accurate placement of guide wire in cannulated screw fixation of femoral neck fracture: A pilot study
}

Bu-Fang Ren ( $\nabla$ rbfdlh123@163.com )

department of orthopedics, the second hospital of shanxi medical university, 382 wuyi road, taiyuan shanxi province, china

Quan-Ping Ma department of orthopedics,the second hospital of shanxi medical university

Xin Lv

department of orthopedics,the second of shanxi medical university

Research article

Keywords: femoral neck fracture, guide, screw,

Posted Date: November 13th, 2020

DOI: https://doi.org/10.21203/rs.3.rs-57323/v3

License: (a) (1) This work is licensed under a Creative Commons Attribution 4.0 International License. Read Full License 


\section{Abstract}

Background: Accurate placement of cannulated screws is the key to stable fixation of the femoral neck fracture. A novel device was developed to improve the accuracy of screw placement.

Methods: 20 synthetic femoral bones were divided into conventional technique group and the experimental group. Three Kirschner wire were inserted into the femoral neck fracture by conventional technique or by the novel guide device. The operative time, total drilling attempts and fluoroscopic frequency were evaluated.

Results: By using the guide device, the fluoroscopy and operation time of the experimental group were shorter that of the conventional method. The total drilling attempts with the novel guide device were significantly lower than the conventional technique group.

Conclusion: This device can help trauma surgeons shorten the surgical time and reduce radiation exposure time. The use of this guide device can make screw fixation for femoral neck fracture easier.

\section{Background}

Femoral neck fracture is a common hip fracture in orthopedics. Internal fixation is preferred for femoral neck fracture in young people and non-displaced femoral neck fracture in elderly people with good physical condition[1,2]. Cannulated screws has been an accepted implant among several implants which have been used for femoral neck fracture[3,4,5]. Placing three cannulated screws in parallel with the inverted triangle can provide better biomechanical stability[6]. However, it is not easy for the surgeons to place screws at the right position. Accurately to insert guide wires accounts for a significant proportion of the total fluoroscopy and operative time.

In this study, the authors designed a novel device for accurate placement of guide wires in cannulated screw fixation of femoral neck fracture. The purpose of this study was to demonstrate the effectiveness of the device.

\section{Materials And Methods}

The device consists of two parts, the aiming part and the fixing part (FIG. 1). The aiming component is a 50-degree angle structure welded by two small stainless steel plates. Two mesh plates with equal size are vertically welded on the surface of a small steel plate. The holes in mesh plates are arranged in parallel columns and rows. The hole diameter is $2.5 \mathrm{~mm}$, and the hole margin is $2 \mathrm{~mm}$. The corresponding holes of the mesh plates form parallel guide channels go pass guide pin. The other plate is welded with a $3.5 \mathrm{~mm}$ Kirschner wire. The fixing assembly is made of two steel buckle welded vertically.

Twenty synthetic right femur specimens with similar bone structure and mechanical characteristics to human bone were obtained from Hangzhou Osborn Technology Co., LTD. The femurs were covered with 
sponge to simulate soft tissue. They were randomly divided into conventional technology group and experimental group. All operative procedures were performed by two attending orthopaedic surgeons.

Surgical Technique

In the conventional technology group: the first guide pin was drilled into the femoral neck at the insertion point $5 \mathrm{~cm}$ below the femoral greater trochanter. Based on anteroposterior and lateral images, the guide pin was adjusted until it was in the inferocentral position of the femoral neck. Then use a parallel guide to place the posterosuperior and anterosuperior pins.

In the experimental group: a 3.0mm Kirschner wire was drilled vertically into the lateral cortex of the upper femur, connecting the guide device and the reference guide pin (Figure 2A). Fluoroscopic imaging was performed to ensure that the reference guide pin was in perfect position on anteroposterior view (Figure $2 \mathrm{~B}$ ) and parallel to the central axis of the femoral neck on lateral view (Figure 2C) by pulling, inserting or rotating the $3.5 \mathrm{~mm}$ Kirschner wire in steel buckle. Its working principle is similar to the operation of inserting the spiral blade of proximal femoral nail antirotation into the femoral neck. Then insert the three guide wires onto the cortical bone surface through the guide channels, and anteroposterior and lateral radiographs of the guidewires were made. The trajectory of the guide wires was drawn on the screen to help to plan their placement in the femoral neck (Figure 3A, 3B). The position of the guide wires in the femur neck on anteroposterior view could be adjusted by the column. The position of the guide wires in the femur neck on lateral view was adjusted by rows. The Kirschner wires were drilled in the femoral neck when they were in the correct position of the femoral neck (Figure 3C, 3D)

Statistical Analysis

This was carried out using SPSS18.0 software (SPSS Inc., Chicago Illiosi) using chi-squared testing. Data are presented as mean \pm standard deviation or numbers, as appropriate The level of significance was set as a $\mathrm{p}$ value $<0.05$

\section{Results}

The results were presented in the Table1.The operative time with the novel device were significantly lower than the operation with the conventional technique ( $\mathrm{p} \otimes 0.05)$. The fluoroscopic frequency and total drilling attempts were also significantly lower in the operation with the novel device (pष0.05).

\section{Discussion}

Closed reduction and internal fixation have become the standard methods for the treatment of femoral neck fractures in patients 60 years of age or younger. Fixation with three parallel cannulated screws placed in an inverted triangle configuration, is a common method for femoral neck fracture [7]. If complication didn't occur, the patient can resume normal activities. The inverted triangle configuration is effective in reducing the rate of nonunion and implant failure [8]. However, accurate guide wire placement 
necessitates high requirement for the surgeon and requires more fluoroscopic and operative time. So, we developed this device to make it easier.

The conventional method of screw placement for femoral neck fractures is mainly performed by surgeons with experience under fluoroscopic monitoring. During the screw fixation of femoral neck fracture with closed reduction, the femoral neck was not exposed and the desired position was not easily obtained due to the lack of necessary reference during the placement of the first guide pin, which often requires multiple drilling for success. Multiple drilling not only resulted in prolonged operation time, increased tissue damage, and increased doctor-patient exposure time to the X-ray radiation, but also can affect the mechanical strength of femoral neck fracture fixation [9].

By using the guide device, the fluoroscopy and operation time of the experimental group were shorter that of the conventional method. This is because in the experimental group, the three guide wires in the femoral neck can be inserted and observed at the same time with one fluoroscopy, while in the control group, each guide wire needs to be fluoroscopy separately. This present study demonstrated three advantage of the device. The first advantage is that the guide wires were accurately inserted in the femoral neck at one time in the experimental group. The hole spacing is $2 \mathrm{~mm}$ in the device, so the position of the guide wires can be slightly adjusted to achieve the best position. The guide channels in the device are parallel. This ensures that the guide wire can be placed in a parallel inverted triangle configuration to the femoral neck. A second advantage is programmed surgical procedures. The surgeon's experience was not important in the experimental group. When the reference guide wire is in the exact position, the guide wire passing through the guide channel must be parallel to the central axis of the femoral neck. The surgeon only needs to select the right channel to insert the three guide wires onto the lateral cortex of the femur in an inverted triangle configuration. The third advantage is that the femoral cortex was not drilled frequently in the experimental group. Drill attempts on the femoral cortex were no more than three times. So the device was easy to operate.

Other researchers have developed guides to accurately place Kirschner wires. Yin et al. demonstrated a novel guidewire aiming device to improve the accuracy of guidewire insertion [10]. However, the operation was complicated. The navigation systems could improve accuracy $[11,12,13]$, but the higher costs of the special instruments and increased radiation and operative time limited their clinical use [14].

\section{Conclusions}

This guide device can significantly improve the accuracy of injection, reduce tissue damage, shorten the operation time and reduce the amount of X-ray radiation. The operator's experience was not important. The use of this device can make percutaneous compression cannulated screw fixation for femoral neck fracture easier.

We believe this guide device can help to promote screw fixation technique in third world countries. This is helpful for an inexperienced hand. However, the utility of this device should be further verified in clinical practice. 


\section{Declarations}

\section{Ethics approval and consent to participate}

The study was approved by the Institutional Review Board/Ethics Committee of the second Hospital of Shanxi Medical University. The study was conducted according to the ethical principles stated in the Declaration of Helsinki

\section{Consent for Publication}

The participants declare that they agree to publish the data described in the manuscript.

\section{Availability of data and material}

The datasets used and analyzed during the current study are available from the corresponding author on reasonable request

\section{Competing interests}

The authors declare that they have no competing interests.

\section{Funding}

Not applicable

\section{Authors' contributions}

Not applicable

\section{Acknowledgements}

Not applicable

\section{References}

1. Davidovitch RI, Jordan CJ, Egol KA, Vrahas MS. Challenges in the treatment of femoral neck fractures in the nonelderly adult. J Trauma.2010; 68(1): 236-242.

2. Bernstein J, Ahn J. In brief: fractures in brief: femoral neck fractures. Clin Orthop Relat Res .2010;468(6): 1713-1715.

3. Seyfettinoglu F, Ersan O, Kovalak E, Duygun F, Ozsar B, Ates Y. Fixation of femoral neck fractures with three screws: results and complications. Acta Orthop Traumatol Turc . 2011;45(1): 6-13

4. Huang HK, Su YP, Chen CM, Chiu FY, Liu CL. Displaced femoral neck fractures in young adults treated with closed reduction and internal fixation.

Orthopedics.2010;33(12):873.Published,2010,Dec,1.doi:10.3928/01477447-20101021-15. 
5. Haidukewych GJ, Rothwell WS, Jacofsky DJ ,Torchia ME,Berry D. Operative treatment of femoral neck fractures in patients between the ages of fifteen and fifty years. J Bone Joint Surg Am. 2004;86$\mathrm{A}(8): 1711-1716$.

6. Selvan VT, Oakley MJ, Rangan A, Al-Lami MK. Optimum configuration of cannulated hip screws for the fixation of intracapsular hip fractures: a biomechanical study. Injury. 2004;35:136-141.

7. Li JT, Wang ML, Zhou JF, Han L, Zhang H, Li C, Li L ,Hao M. Optimum Configuration of Cannulated Compression Screws for the Fixation of Unstable Femoral Neck Fractures: Finite Element Analysis Evaluation.Biomed Res Int. 2018;9;1-10.

8. Yang JJ, Lin LC, Chao KH, Chuang SY, Wu CC, Yeh TT, Lian YT. Risk factors for nonunion in patients with intracapsular femoral neck fractures treated with three cannulated screws placed in either a triangle or an inverted triangle configuration. J Bone Joint Surg Am.2013;95(1):61-69.

9. Mei J, Liu S, Jia GY, Cui XL, Jiang C, Ou Y. Finite element analysis of the effect of cannulated screw placement and drilling frequency on femoral neck fracture fixation. Injury.2014;45(12):2045-2050.

10. Yin WJ, Xu HT, Hu T, An ZQ, Zhang CQ, Sheng JG. A novel guidewire aiming device to improve the accuracy of guidewire insertion in femoral neck fracture surgery using cannulated screw fixation. Med Sci Monit. 2016;16;22:2893-2899.

11. Liebergall M, Ben-David D, Weil Y, Peyser A, Mosheiff R. Computerized navigation for the internal fixation of femoral neck fractures. J Bone Joint Surg Am. 2006;88:1748-1754.

12. Kendoff D, Hüfner T, Citak M, Geerling J, Maier C, Wesemeier F,Krettek C. Implementation of a new navigated parallel drill guide for femoral neck fractures. Comput Aided Surg. 2006;11:317-321.

13. Kendoff D, Hüfner T, Citak M, Maier C, Wesemeier F, Pearle A, Krettek C. A new parallel drill guide for navigating femoral neck screw placement. Development and evaluation. Unfallchirurg. 2006;109:875-880.

14. Muller MC, Belei P, Pennekamp PH, Kabir K, Wirtz DC, Burger C, Weber O. Three-dimensional computer-assisted navigation for the placement of cannulated hip screws. A pilot study. Int Orthop. 2012;36(7)1463-1469.

\section{Table}

Table 1: Comparison of results in the two groups. The values are given as the mean and the standard deviation. Statistical significance was defined for $\mathrm{p} \leq 0.05$.

\begin{tabular}{|c|c|c|c|}
\hline Result & Experimental group & Conventional group & P \\
\hline $\begin{array}{c}\text { Operation } \\
\text { Time (min) }\end{array}$ & $20.8 \pm 8.1$ & $38.3 \pm 5.6$ & 0.04 \\
\hline $\begin{array}{c}\text { Fluoroscopy } \\
\text { Frequency(number) }\end{array}$ & $6.5 \pm 3.6$ & $16.7 \pm 8.4$ & 0.01 \\
\hline Total drilling times & $3.0 \pm 0$ & $16.9 \pm 4.2$ & 0.01 \\
\hline
\end{tabular}

\section{Figures}




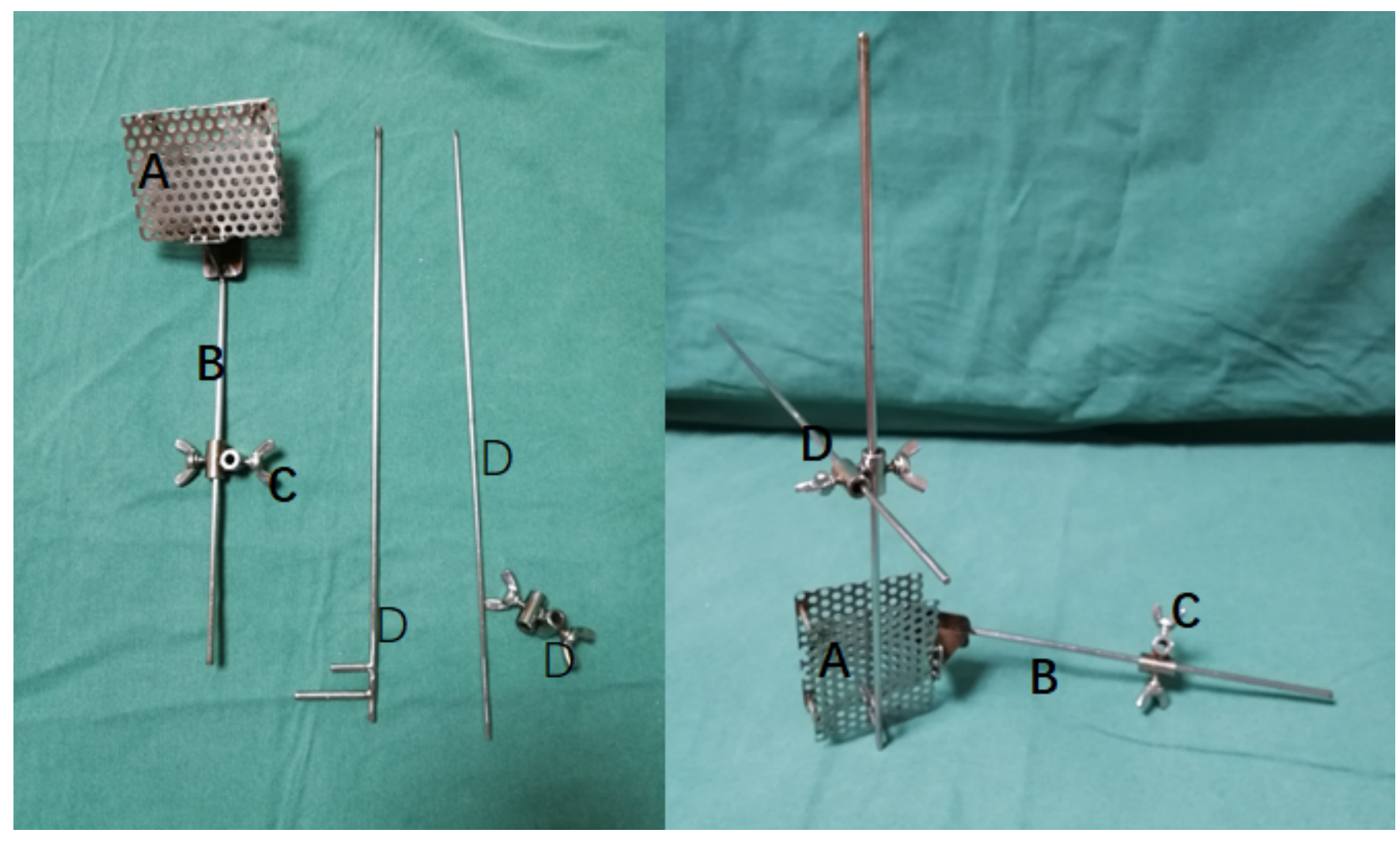

\section{Figure 1}

Picture of the guide device. (A) the aiming part ;(B) 3.5mm Kirschner wire; (C) the fixing part; (D) the reference guide pin

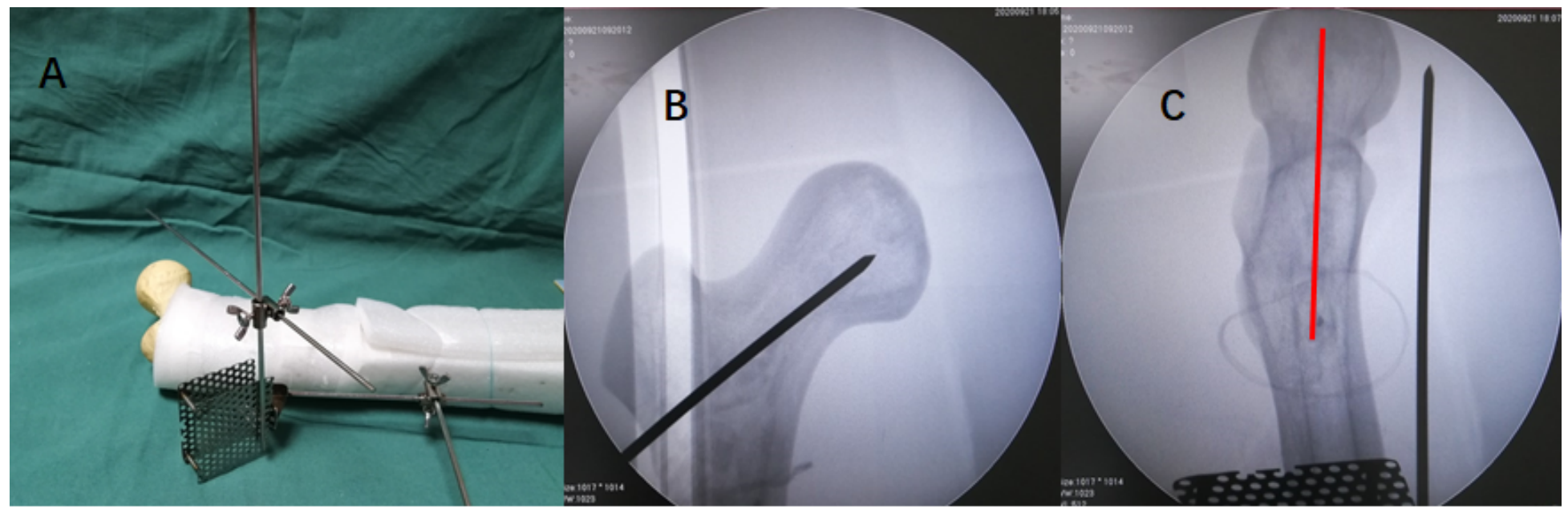

\section{Figure 2}

(A)The guide device was fixed on the surface of the femoral cortex and fluoroscopic imaging was performed $(B, C)$. (B)The reference guide wire was in the inferior position of the femoral neck on anteroposterior imaging. (C)The reference guide wire was parallel to the central axis of the femoral neck on lateral imaging. 


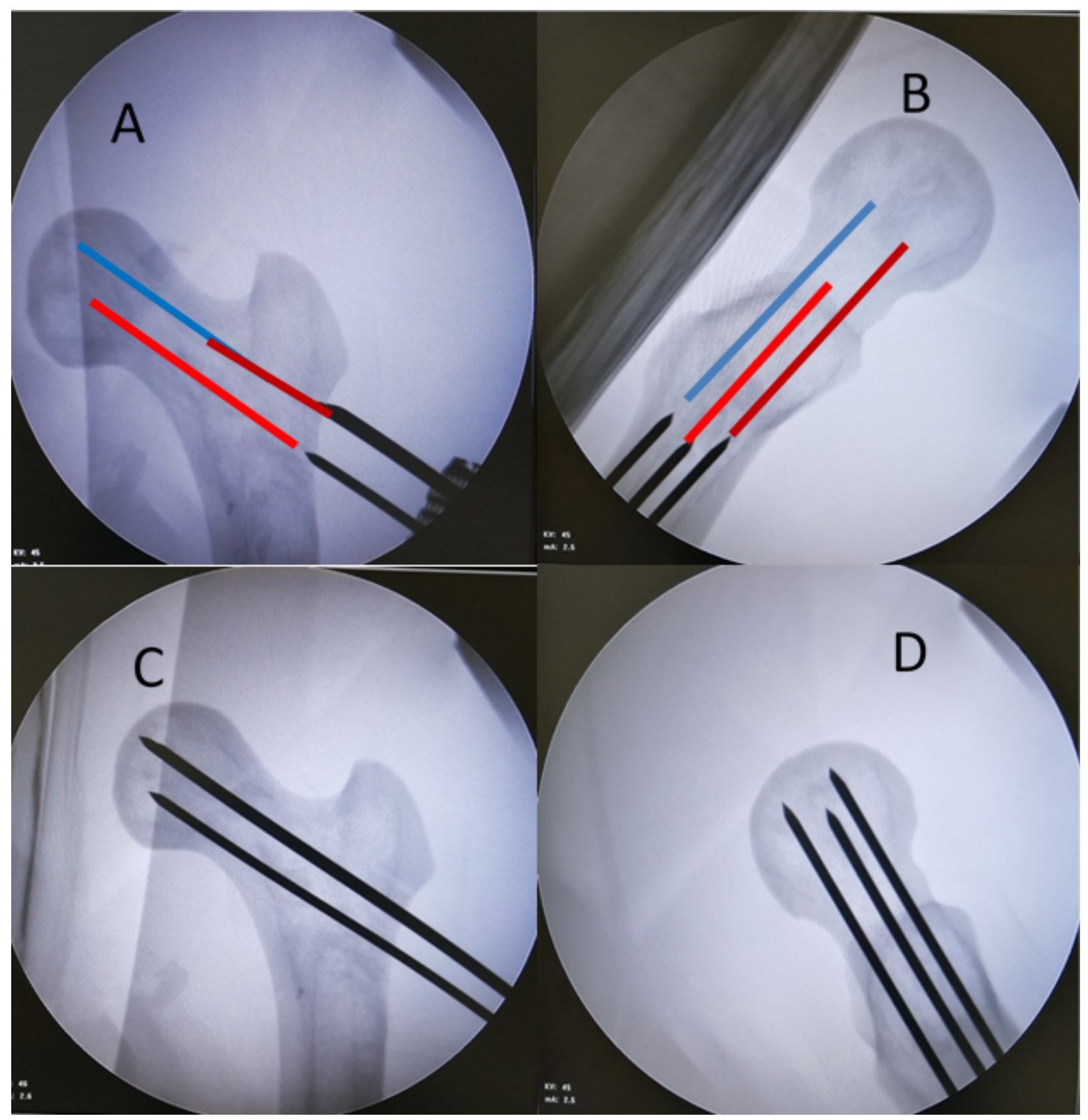

Figure 3

Insertion of the three guide wires: Anteroposterior $(A, C)$ and lateral $(B, D)$ fluoroscopic images were acquired. The trajectory of the guide wires (the red, green and blue lines in the $A, B$ ) in the femoral neck on the previously acquired anteroposterior and lateral radiographs is drawn. The guide wires were drilled into the femoral neck (C, D). 